\title{
Desempenho de novilhos de corte em pastagem nativa com níveis de suplementação de farelo de arroz integral
}

\author{
Beef steers performance in natural pasture with levels of full fat rice brain supplementation
}

\author{
Maria Beatriz Fernandez Gonçalves ${ }^{1}$ Enio Rosa Prates ${ }^{\text {II }}$ Alexandre Coradini Fontoura da Silva ${ }^{\text {III }}$ \\ Naíme de Barcellos Trevisan ${ }^{\mathrm{III}}$ Geórgia Biscaíno ${ }^{\mathrm{III}}$
}

\section{RESUMO}

Este trabalho teve por objetivo avaliar o desempenho de novilhos de corte em pastagem nativa $(P N)$, suplementados com níveis de farelo de arroz integral (FAI) de $0 ; 0,5 ; 1,0$ e 1,5\% do peso vivo dos animais, num delineamento inteiramente casualizado em parcelas subdivididas, durante 126 dias. Na parcela principal, foram alocados os níveis de suplemento e, nas subparcelas, os períodos de tempo (6 períodos de 21 dias). A suplementação foi oferecida de forma individual, duas vezes por dia, às 7 h e às 15h:30min. O método de pastejo empregado foi o contínuo com lotação fixa e carga variável. As médias encontradas para proteína bruta foram de 6,8 e 14,9\%, e para os coeficientes de digestibilidade "in vitro" da matéria orgânica, foram de 59,54 e 71,47\% na PN e no FAI, respectivamente (dados expressos na matéria seca). Os ganhos médios diários dos animais foram de 0,35; 0,55; 0,53; e $0,63 \mathrm{~kg}_{\text {animal }}{ }^{-1}$ dia $^{-1}$ para os níveis de inclusão de farelo de arroz de $0 ; 0,5 ; 1,0$ e 1,5\% do peso vivo dos animais, diferindo entre animais suplementados e não-suplementados. Os resultados de rendimento e peso de carcaça fria dos animais não diferiram entre os tratamentos. A suplementação com FAI nos níveis entre 0,5 a 1,5\% proporcionou incremento no ganho médio diário de aproximadamente 60\%, quando comparado com os animais que não receberam suplemento.

Palavras-chave: ganho peso vivo diário, campo nativo, suplemento, pastejo contínuo, peso de carcaça.

\section{ABSTRACT}

This study was aimed at investigating steers performance on native pasture supplemented with levels of full fat rice bran: $0 ; 0.5 ; 1.0$ and $1.5 \%$ of body weight of the animals, in a completely randomized design, with a split plot arrangement, during 126 days. In main plots were allocated the levels of supplement and in a split plot, the periods of time (6 periods of 21 days each). The supplementation was individual, offered twice a day, at 7am and 3.3pm. The system of pasture was continuous grazing with fix stocking density and variable stocking rate. The average percent of crude protein were $6.8 \%$ and $14.9 \%$ and the in vitro digestibility coefficients were $59.54 \%$ and $71.47 \%$ in native pasture and rice bran, respectively (in the dry matter). The live weight gains of the animals were $0.35 ; 0.55 ; 0.53$ and $0.63 \mathrm{~kg} \mathrm{~d}^{-1}$ with the rice bran daily inclusion of $0.0 ; 0.5 ; 1.0$ and $1.5 \%$ of the animals live weigh differing only when it was considered the use or not use of the supplement. The carcass yield and weigh do not differ among the treatments. The supplementation with full fat rice bran in the levels between $0.5 \%$ and $1.5 \%$ of live weight proportioned an increase on the live weigh gain of approximately $60 \%$ when compared with the animals that did not receive supplement.

Key words: daily live weigh gain, native pasture, supplement, continuous grazing, carcass weight.

\section{INTRODUÇÃO}

A suplementação, através do uso de concentrados energéticos e de seus subprodutos, no período hibernal, é uma das alternativas disponíveis para a alimentação de bovinos mantidos exclusivamente em pastagens nativas no Rio Grande do Sul (RS). Estas pastagens representam aproximadamente $37 \%$ da superfície pastoril total do Estado (IBGE, 2000) e caracterizam-se por apresentar variações quantiqualitativas ao longo do ano, ocasionando alterações de ordem nutricional ao rebanho e contribuindo para reduzir os índices zootécnicos.

${ }^{1}$ Departamento de Zootecnia, Universidade Federal de Santa Maria (UFSM), Santa Maria, RS, Brasil. Rua Appel, 655, ap. 804, 97015-030, Santa Maria, RS, Brasil. E-mail: mbeatriz.voy@terra.com.br. Autor para correspondência.

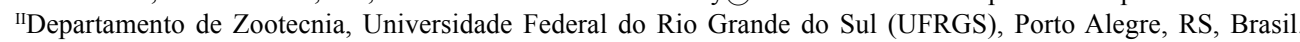

IIIPrograma de Pós-graduação em Zootecnia, UFSM, Santa Maria, RS, Brasil. 
Entre os alimentos concentrados mais utilizados destacam-se o grão de milho e o farelo de soja, que representam a base da dieta das atividades avícola e suinícola. Estes alimentos possuem cotações influenciadas pelo mercado externo, inviabilizando, na maioria dos casos, seu uso para a alimentação de bovinos de corte. Diante desse cenário, verifica-se a necessidade de estudos para a avaliação de suplementos alternativos, que aliem resultados biológicos satisfatórios com custos reduzidos.

No RS, a lavoura orizícola possui importante expressão econômica. As produções médias anuais, considerando as últimas cinco safras, foram de 5,4 milhões de toneladas de arroz em casca (IRGA, 2005). O beneficiamento deste grão gera quantidades significativas de subprodutos, com destaque para o farelo de arroz integral. Sua participação representa, normalmente, entre 8 e $10 \%$ do total de arroz colhido, o que equivale a aproximadamente 430 mil toneladas, com bom potencial energético e protéico.

O objetivo deste trabalho foi avaliar o desempenho de bovinos de corte, em pastagem nativa, recebendo diferentes níveis de suplementação de farelo de arroz integral durante o período hibernal.

\section{MATERIAL E MÉTODOS}

O experimento foi realizado na Agropecuária LP, localizada no município de São Gabriel, situado na região da Depressão Central do Rio Grande do Sul. O clima da região é subtropical úmido (Cfa), conforme a classificação de Köppen (MORENO, 1961), e o solo pertence à unidade de mapeamento São Pedro, classificado como ARGISSOLO VERMELHO Distrófico Arênico (EMBRAPA, 1999).

O período de avaliação, compreendido entre fevereiro e julho, totalizou 154 dias, dos quais os primeiros 28 dias foram destinados à adaptação dos animais. O período experimental teve início em 18/03/ 00 e término em 22/07/2000, sendo dividido em seis sub-períodos de 21 dias cada.

A área experimental se constituiu em um único piquete de aproximadamente 30 hectares, coberto por vegetação nativa. $\mathrm{O}$ propósito disto foi manter os animais em condições semelhantes, para que, efetivamente, pudessem ser verificados apenas os efeitos dos tratamentos a serem impostos. Nessa pastagem, as espécies de crescimento estival tiveram a maior participação na formação da massa de forragem. As maiores freqüências foram das gramíneas dos gêneros Paspalum, Axonopus, Andropogon e Schizachyrium e de leguminosas do gênero Desmodium e Adesmia. Anteriormente ao início do período de adaptação dos animais, a pastagem nativa
(PN) foi roçada, permanecendo diferida por um período de 25 dias.

O método de pastejo adotado foi o contínuo, com lotação fixa e carga variável. A massa de forragem presente na $\mathrm{PN}$ foi estimada mensalmente pelo método da estimativa visual direta com dupla amostragem (MANNETJE, 2000). Estas se constituíram de 20 observações visuais e cinco cortes da vegetação rente ao solo.

Foram utilizados 25 novilhos castrados, com idade e peso vivo (PV) médios de 16 meses $( \pm 1,5)$ e 228 $\mathrm{kg}( \pm 9,7)$, respectivamente, ao início do período experimental. Estes animais eram oriundos de cruzamento entre as raças Hereford, Nelore e Aberdeen Angus e foram pesados ao término de cada subperíodo experimental, após jejum de sólidos e líquidos de 12 horas. O manejo sanitário empregado seguiu a rotina da propriedade, constituindo-se em controles carrapaticidas, mosquicidas e everminações, além das vacinas necessárias. $\mathrm{O}$ sal comum foi o suplemento mineral disponibilizado aos animais, ad libitum.

Os tratamentos inicialmente previstos eram constituídos por níveis de suplementação de farelo de arroz integral (FAI) de $0 ; 0,5 ; 1,0 ; 1,5$ e $2,0 \%$ do PV dos animais, em base de amostra como é oferecida. O FAI foi adquirido periodicamente, em quantidades suficientes para um período de 30 dias, com a finalidade de evitar a rancificação do produto. Ao farelo era acrescido calcário calcítico visando a manter a relação cálcio:fósforo na proporção de 1,5:1,0.

A suplementação foi oferecida em duas refeições diárias, às 7 e às 15h:30min, em baias individuais que possuíam área média de $7,8 \mathrm{~m}^{2}$ e estavam localizadas a aproximadamente $500 \mathrm{~m}$ do piquete, sob uma floresta de eucalipto. Os níveis de suplementação foram ajustados a cada 21 dias, considerando o PV de cada animal.

Após o período destinado ao consumo, havendo sobras, estas eram retiradas, pesadas e registradas para os cálculos de consumo individual. $\mathrm{O}$ consumo foi determinado pela diferença entre a quantidade da mistura de FAI e calcário oferecidas e as sobras existentes nos cochos, coletadas após cada refeição. Pela natureza farelada do suplemento e pela ocorrência de vento, muitas vezes observavam-se sobras no solo que não foram consideradas. Ao término do experimento, independentemente do grau de acabamento, os animais foram abatidos e suas carcaças pesadas para o cálculo do rendimento percentual de carcaça fria.

Foram determinados os teores de matéria seca (MS), proteína bruta (PB), cálcio $(\mathrm{Ca})$ e fósforo $(\mathrm{P})$ das partidas de FAI (AOAC, 1995). Nas amostras da pastagem nativa, foram determinados os teores de $\mathrm{PB}$ 
e de digestibilidade in vitro da matéria orgânica (DIVMO)(TYLLEY \& TERRY,1963).

Inicialmente foi desenhado um delineamento inteiramente casualizado em parcelas subdivididas, nas quais os níveis de suplemento foram as parcelas e os períodos de tempo as subparcelas, segundo o modelo estatístico:

$$
\mathrm{Y}_{\mathrm{ijk}}=\mu+\mathrm{T}_{\mathrm{i}}+\mathrm{R}_{\mathrm{j}}\left(\mathrm{T}_{\mathrm{i}}\right)+\mathrm{P}_{\mathrm{k}}+(\mathrm{Tp})_{\mathrm{ik}}+\mathrm{ei}_{\mathrm{jk}}
$$

Onde: $\mathrm{Y}_{\mathrm{ij}} \stackrel{\mathrm{i}}{=}$ variável dependente referente ao tratamento $\mathrm{i} ; \mu=$ média geral das observações; $\mathrm{T}_{\mathrm{i}}=$ efeito dos níveis de farelo de arroz, sendo $\mathrm{i}=0 ; 0,5 ; 1,0$ e $1,5 \%$ do peso vivo dos animais; $\mathrm{R}_{\mathrm{j}}\left(\mathrm{T}_{\mathrm{i}}\right)=$ efeito da repetição dentro dos tratamentos; $\mathrm{P}_{\mathrm{k}}=$ efeito de período; $(\mathrm{Tp})_{\mathrm{ik}}=$ interação tratamento período; $\mathrm{e}_{\mathrm{ijk}}=$ erro aleatório ou amostral.

Pelo modelo, existem dois tipos de unidades experimentais. Uma delas é a unidade animal, da qual foram verificados os ganhos de peso. A outra unidade constitui-se em animal-período, que está relacionada ao ganho de peso do mesmo animal em diferentes períodos.

Como alguns animais se recusaram a consumir as quantidades pré-estabelecidas de FAI, os tratamentos foram reagrupados, utilizando-se a análise de conglomerados (Cluster) como método de reagrupamento. Assim, foram testados quatro níveis de inclusão de farelo de arroz, de $0 ; 0,5 ; 1,0$ e 1,5\% do peso vivo dos animais, com 5, 6, 7 e 6 unidades experimentais, respectivamente, num total de 24 animais.

Os resultados foram interpretados estatisticamente por meio de análise de variância através do procedimento PROC GLM (SAS 6.08, 1997), e as médias dos tratamentos foram testadas pelo teste F, em nível de 5\% de probabilidade. Quando houve diferença, as médias foram comparadas pelo teste de Tukey. Para analisar os efeitos dos níveis de FAI sobre a variável estudada, optou-se pelo modelo de regressão cúbica, pois foi o que melhor se ajustou com coeficiente de determinação dos dados de 0,6683 . O modelo resultante foi o seguinte: $Y_{i j k}=\beta 0+\beta 1_{x i j}+\beta 2 x^{2}{ }_{i j}+\beta 3 x^{3}{ }_{i j}$ $+\gamma_{\mathrm{ijk}}$, em que: $\beta 0$ representa a constante da equação; ß1, ß2 e $\beta 3$ são os coeficientes de regressão linear, quadrática e cúbica e $\gamma \mathrm{ijk}=$ desvios da regressão.

\section{RESULTADOS E DISCUSSÃO}

Em sistema de pastejo contínuo, sem ajuste da carga animal, podem ocorrer, em determinados períodos de utilização, incrementos ou reduções nas massas de forragem como conseqüência de alterações das taxas de acúmulo diárias. As massas de forragem observadas foram de $1.975 ; 1.473 ; 1.225 ; 1.163$ e $1.090 \mathrm{~kg}$ ha $^{-1}$ de MS nas datas de 09/04; 30/04; 19/05; 21/06 e 18/ 07/2000, respectivamente, o que conferiu valor médio de $1.385 \mathrm{~kg} \mathrm{ha}^{-1}$ de MS durante o experimento. Este valor é semelhante aos $1.365 \mathrm{~kg} \mathrm{ha}^{-1}$ de MS mantidos durante o período hibernal e que representam o resultado da imposição de diferentes ofertas de forragem avaliadas por SOARES (2002) em PN da Depressão Central do Rio Grande do Sul.

Ao longo do período experimental, observase uma tendência de redução nos valores de PB e DIVMO da PN, conforme apresentado na tabela 1. Isso está relacionado à senescência das espécies de ciclo metabólico $\mathrm{C}_{4}$ e ao conseqüente aumento da lignificação da parede celular. $\mathrm{O}$ resultado médio de $\mathrm{PB}$ inferior a $7 \%$ da MS na pastagem nativa é considerado por VAN SOEST (1994) como limitante ao desenvolvimento da população microbiana do retículo-rúmen, podendo afetar o consumo e a digestibilidade do alimento disponível. Soma-se a isso a falta de práticas adequadas de manejo da pastagem nativa para justificar as freqüentes perdas de peso e os baixos índices de produtividade verificados no RS nesta época do ano.

Tabela 1 - Valores, por período e média, de proteína bruta (PB), de digestibilidade in vitro da matéria orgânica (DIVMO), de nutrientes digestíveis totais (NDT), de cálcio (Ca) e de fósforo (P), expressos em percentagem da matéria seca, de amostras de pastagem nativa e de farelo de arroz integral. São Gabriel, RS.

\begin{tabular}{|c|c|c|c|c|c|c|c|}
\hline & \multicolumn{6}{|c|}{ Períodos } & \multirow[b]{2}{*}{ Média } \\
\hline & $18 / 03$ a $07 / 04$ & $08 / 04$ a $28 / 04$ & $29 / 04$ a $20 / 05$ & $21 / 05$ a $09 / 06$ & $10 / 06$ a $30 / 06$ & $01 / 07$ a $22 / 07$ & \\
\hline & \multicolumn{7}{|c|}{ Pastagem nativa (\% na MS) } \\
\hline PB & 8,1 & 7,8 & 7,1 & 6,0 & 6,3 & 5,5 & 6,8 \\
\hline DIVMO & 64,32 & 62,28 & 60,32 & 58,07 & 57,15 & 55,10 & 59,54 \\
\hline $\mathrm{Ca}$ & 0,25 & 0,34 & 0,22 & 0,38 & 0,16 & 0,29 & 0,27 \\
\hline \multirow[t]{2}{*}{$\mathrm{P}$} & 0,07 & 0,10 & 0,10 & 0,09 & 0,07 & 0,06 & 0,08 \\
\hline & \multicolumn{7}{|c|}{ Farelo de arroz integral (\% na MS) } \\
\hline PB & 15,1 & 13,4 & 14,9 & 14,2 & 16,2 & 15,8 & 14,9 \\
\hline NDT & 73,05 & 71,24 & 75,32 & 70,05 & 68,85 & 70,28 & 71,47 \\
\hline $\mathrm{Ca}$ & 0,04 & 0,05 & 0,05 & 0,04 & 0,03 & 0,04 & 0,04 \\
\hline $\mathrm{P}$ & 2,09 & 2,29 & 1,99 & 2,10 & 2,13 & 2,00 & 2,10 \\
\hline
\end{tabular}


Como as amostras da avaliação da PN foram oriundas do corte de toda a vegetação presente, inferese que a forragem efetivamente consumida pelos animais poderia apresentar qualidade superior a dos resultados obtidos, em função da seletividade no ato de pastejo. Nesse sentido, avaliando características da PN e da dieta, DENARDIN-SALDANHA (1989) verificou uma diferença de $70 \%$ nos valores de PB e DIVMO entre a dieta selecionada e a parcela avaliada, o que explica em parte os resultados obtidos de desempenho para os animais do tratamento testemunha deste trabalho (Figura 1), os quais podem ser considerados elevados para o período considerado.

Para animais com peso vivo e taxas de crescimento semelhantes aos deste trabalho, a exigência nutricional de cálcio e fósforo é de 13 e $5 \mathrm{~g}$ $\mathrm{dia}^{-1}$, respectivamente (NRC, 2000). Isso resulta em relação $\mathrm{Ca}: \mathrm{P}$ de 2,6:1, próximo ao valor recomendado por MARTIN (1993), de 2,0:1, pois se supõe que esta seja a mais adequada para o crescimento e formação óssea de bovinos. Na PN, esta relação manteve-se entre 2,2:1 e 4,83:1 durante o experimento. Para o FAI, esta relação foi, em média, $0,02: 1$, justificando a inclusão do calcário calcítico.

A oferta de um alimento com composição bromatológica superior à pastagem proporcionou aos animais suplementados desempenho significativamente superior àqueles alimentados exclusivamente com $\mathrm{PN}$. Este efeito também foi observado por SANTOS et al. (1997), que observaram ganhos individuais de $0,42 \mathrm{~kg}$ animal dia $^{-1}$ com novilhos em pastagem nativa, recebendo FAI em nível de $0,5 \%$ do PV durante o período outonal.

Entre os tratamentos, o GMD dos animais suplementados foi estatisticamente semelhante, indicando um possível efeito substitutivo no consumo da pastagem na medida em que o nível de suplementação aproximava-se de $1 \%$ do PV dos animais. Para HORN et al. (1995), as possíveis interações negativas do amido sobre a digestibilidade da fibra, especialmente quando fornecidos níveis superiores a $1 \%$ do PV do animal, são responsáveis pela ocorrência do efeito substitutivo sobre o consumo total de MS. A curva estimada pela equação cúbica apresentada na figura 1 mostra que o desempenho animal foi incrementado até o nível de $0,5 \%$ do PV de suplementação, com pouca alteração em níveis superiores a este. Essa tendência é confirmada por PARDO et al. (2003), que, ao fornecerem grão de sorgo moído a novilhos de corte, verificaram ganhos individuais de 0,$15 ; 0,48$ e $0,48 \mathrm{~kg}_{\text {animal }}{ }^{-1} \mathrm{dia}^{-1} \mathrm{com}$ níveis de suplementação de $0 ; 0,75$ e 1,5\% do PV, respectivamente, no período de 11/08 a 06/09.

A ausência de incremento significativo no desempenho animal, com maiores níveis de suplementação, pode ser explicada também pela redução da digestibilidade ruminal da MS ou mesmo da fibra, devido à possível queda do $\mathrm{pH}$ ruminal e às relações desfavoráveis entre energia e proteína degradável. Os efeitos negativos sobre o consumo e a digestibilidade ruminal seriam observados em maior magnitude a partir de um nível de suplementação de $0,8 \%$ do PV dos animais (CATON \& DRUYVETTER, 1997). Para FOSTER et al. (1993), o elevado teor de gordura e amido do farelo de arroz também podem ser os responsáveis pela baixa digestibilidade da matéria orgânica deste alimento.

Ao término do experimento, os animais foram abatidos, independentemente do peso e do grau de deposição de gordura subcutânea desejados. Assim, os rendimentos de carcaça (Tabela 2 ) foram inferiores a $50 \%$ em todos os tratamentos, não diferindo entre estes.

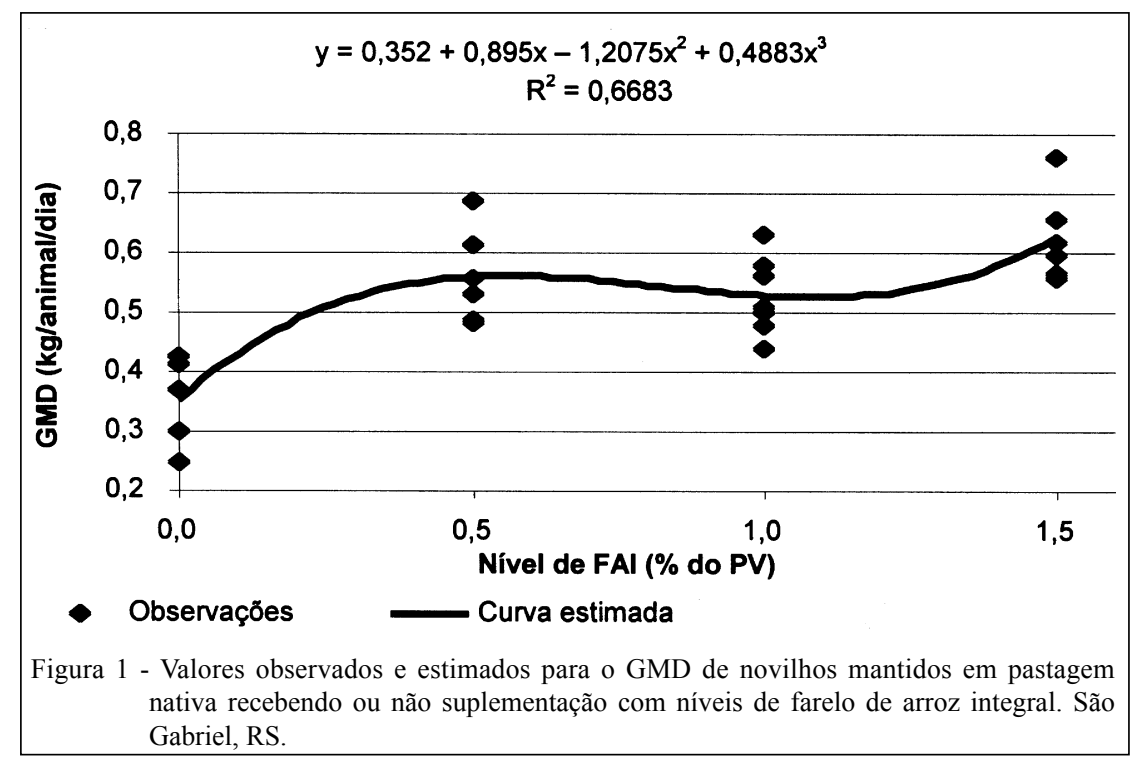

Ciência Rural, v.37, n.2, mar-abr, 2007. 
Tabela 2 - Conversão alimentar do suplemento ( $\mathrm{kg}$ de farelo de arroz integral consumido/kg de ganho de $\left.\mathrm{PV}^{-1}\right)$, peso de carcaça fria (kg) e rendimento de carcaça fria (\%) de novilhos mantidos em pastagem nativa recebendo ou não suplementação com níveis de farelo de arroz integral. São Gabriel, RS.

\begin{tabular}{cccc}
\hline $\begin{array}{c}\text { Tratamentos (\% do peso vivo em } \\
\text { farelo de arroz integral) }\end{array}$ & $\begin{array}{c}\text { Conversão alimentar }(\mathrm{kg} \\
\text { consumido/kg de ganho de PV) }\end{array}$ & $\begin{array}{c}\text { Peso de carcaça fria } \\
(\mathrm{kg})\end{array}$ & $\begin{array}{c}\text { Rendimento de carcaça fria } \\
(\%)\end{array}$ \\
\hline 0 & - & $126,33 \mathrm{a}$ & $46,67 \mathrm{a}$ \\
0,5 & 3,72 & $139,16 \mathrm{a}$ & $47,16 \mathrm{a}$ \\
1,0 & 8,17 & $143,33 \mathrm{a}$ & $47,86 \mathrm{a}$ \\
1,5 & 7,64 & $152,98 \mathrm{a}$ & $49,18 \mathrm{a}$ \\
\hline
\end{tabular}

Letras iguais na mesma coluna indicam semelhança entre as médias em nível de $5 \%$ de significância pelo teste de Tukey.

Da mesma forma, os pesos de carcaça fria não diferiram entre os níveis de suplementação avaliados. Esses pesos, que, na média, foram de $140 \mathrm{~kg}$, estão abaixo do peso desejado pelos frigoríficos - cerca de $220 \mathrm{~kg}$ de carcaça fria - para que sejam diluídos custos operacionais do abate. Além disso, são considerados baixos para esta categoria animal quando comparados com trabalhos analisados por RESTLE \& VAZ (2003), e podem acarretar em deságio no momento da comercialização para abate.

Melhorar a eficiência econômica das propriedades rurais e ajustar o fluxo de caixa às despesas mensais requer, entre outras alternativas, escalonar o abate dos animais durante o ano. Biologicamente, isso significa reduzir o número de categorias em desenvolvimento no rebanho, destinando animais jovens (como os empregados nesta pesquisa) para terminação. Carcaças mais adequadas ao mercado poderiam ser obtidas respeitando as exigências nutricionais dos animais no período de recria, como forma de otimizar o desenvolvimento corporal dos animais.

\section{CONCLUSÕES}

A inclusão de farelo de arroz integral em nível de $0,5 \%$ do peso vivo dos animais proporciona incremento no desempenho de novilhos de corte em pastagem nativa do Rio Grande do Sul durante o período de outono-inverno.

A suplementação de farelo de arroz integral, em sistemas pastoris baseados em campo nativo, nos níveis entre 0,5 e $1,5 \%$ do peso vivo, proporciona aumento médio no ganho diário em aproximadamente $60 \%$ quando comparado com animais nãosuplementados, o que pode contribuir para a elaboração de uma estratégia de alimentação e, conseqüentemente, de programação de abates ao longo do ano.

\section{AGRADECIMENTOS}

Ao Instituto Rio Grandense do Arroz (IRGA), à Fundação de Amparo à Pesquisa do Estado do Rio Grande do sul (FAPERGS) e a JOSAPAR, pelo apoio dado durante a realização deste trabalho.

\section{REFERÊNCIAS}

AOAC - Association of official analytical chemists. Official methods of analysis. 15.ed. Washington, DC, 1995. $1094 \mathrm{p}$.

CATON, J.S.; DHUYVETTER, D.V. Influence of energy supplementation on grazing ruminants. Journal of Animal Science, v.75, p.533-542, 1997.

DENARDIN-SALDANHA, C.E. Avaliação do rendimento e composição botânica de uma pastagem natural e da dieta selecionada por animais em pastejo. 1989. $159 \mathrm{f}$. Dissertação (Mestrado em Zootecnia) - Curso de Pós-graduação em Zootecnia, Universidade Federal de Santa Maria.

EMBRAPA, Centro Nacional de Pesquisa de Solos. Sistema Brasileiro de classificação de solos. Rio de Janeiro: EMBRAPA, 1999. 412p.

FOSTER, L.A.J. et al. Feed intake, digestibility and live weight gain by cattle consuming forage supplemented with rice bran and (or) corn. Journal of Animal Science, v.71, p.3105$3122,1993$.

HORN, G.W. et al. Influence of high starch vs high-fiber energy supplements on performance of stocker cattle grazing wheat pasture and subsequent feedlot performance. Journal of Animal Science, v.73, n.1, p.45-54, 1995.

IBGE - Instituto Brasileiro de Geografia e Estatística. Anuário Estatístico Brasileiro, Rio de Janeiro, v.56, p.1-1-8-32, 2000

IRGA - Instituto Rio Grandense do Arroz. Arroz irrigado no RS - Área, produção e rendimento, Porto Alegre, 03 jun. 2005. Capturado em 03 jun, 2005. On line. Disponível na Internet: http://www.irga.rs.gov.br.

MANNETJE, L.T'. Measuring biomass of grassland vegetation. In: MANNETJE, L.T'; JONES, R.M. Field and laboratory methods for grassland and animal production research. Cambridge: CABI, 2000. p.151-178. 
MARTIN, L.C.T. Nutrição mineral bovinos de corte. São Paulo: Nobel, 1993. 173p.

MORENO, J.A. Clima do Rio Grande do Sul. Porto Alegre : Secretaria da Agricultura, 1961. 41p.

NRC - NATIONAL RESEARCH COUNCIL. Nutrient Requirement of Beef Cattle. Washington: National Academy, 2000. 232p.

PARDO, R.M.P. et al. Níveis crescentes de suplementação energética sobre o desenvolvimento de novilhos mantidos em pastagem natural na encosta sudeste do Rio Grande do sul. Revista Brasileira de Zootecnia, v.32, n.6, p.1397-1407, 2003.

RESTLE, J.; VAZ, F.N. Eficiência e qualidade na produção de carne bovina. In.: REUNIÃO ANUAL DA SOCIEDADE BRASILEIRA DE ZOOTECNIA, 40., 2003, Santa Maria, RS. Anais... Santa Maria: Sociedade Brasileira de Zootecnia, 2003. $1 \mathrm{CD}$.
SANTOS, R.P. et al. Diferentes tipos de suplementos concentrados para novilhos de corte em fase de recria. In JORNADA ACADÊMICA INTEGRADA DE PESQUISA, EXTENSÃO E ENSINO, 4., 1997, Santa Maria, RS. Anais... Santa Maria: Universidade Federal de Santa Maria, 1997. p.807.

SAS INSTITUTE. Statistical analysis system user's guide. Version 6.08. Cary, 1997. 1014p.

SOARES, A.B. Efeito da alteração da oferta de matéria seca de uma pastagem natural sobre a produção animal e a dinâmica da vegetação. 2002. 180f. Tese (Doutorado em Zootecnia) - Programa de Pós-graduação em Zootecnia, Universidade Federal do Rio Grande do Sul.

TYLLEY, J.M.A.; TERRY, R.E. A two stages technique for the in vitro digestion of forage crops. Journal British Grassland Society Hurley, v.18, n.2, p.104-111, 1963.

VAN SOEST, P.J. Nutricional ecology of the ruminant. London: Constock Publishing Associates, 1994. 476p. 